\title{
The Effect of Nanoparticle Additive on the Mechanical Properties of Glass Fiber Composite Materials
}

\author{
C. TUNCER ${ }^{a}$ AND O.E. CANYURT ${ }^{b *}$ \\ ${ }^{a}$ Pamukkale University, Department of Mechanical Engineering, 20160 Pamukkale/ Denizli, Turkey \\ ${ }^{b}$ Gazi University, Technology Faculty, Industrial Design Engineering, 06500, Teknikokullar/Ankara, Turkey \\ In this study, the effects on the tensile strength of E-glass/epoxy composite materials produced using graphene \\ nanoparticles were investigated experimentally. The graphene nanoparticle composite was used at $0.1 \%, 0.3 \%$, \\ and $0.5 \%$ by weight of the composite plate. The effect of angled orientation and addition of nanoparticles on \\ the composite sandwich structures were examined. The load carrying capability of composite was significantly \\ influenced by graphene nanoparticles. Experimental results and scanning electron microscopy analysis of the \\ present study indicate that failure was mainly caused by fiber and matrix failure. Matrix properties were improved \\ by adding graphene nanoparticles. The amount of $0.1 \%$ graphene additive led to $20 \%$ increase in the composite \\ strength. Optimum amount of graphene was determined experimentally.
}

DOI: 10.12693/APhysPolA.135.752

PACS/topics: glass, fiber, graphene, epoxy, tensile strength

\section{Introduction}

The matrix material can be metallic, polymeric, and ceramic. In recent years, nanoparticle reinforced polymer composites have attracted attention in material sciences due to their low weight and higher strength compared with materials like metals. The use of nanoparticle reinforced polymer matrix composite materials in industrial application is grooving due to their high strength/stiffness to low weight ratio, ease of fabrication, corrosion resistance, ease of fabrication, environmentally friendly and economically efficient properties [1].

Nanoparticle reinforced polymer composite materials have thus become popular material in aerospace, automotive, chemical, defense, and construction industries, for using in glass fiber composite materials and carbon fiber composite materials that have relatively poor thermal conductivity. Nowadays, nanoparticle added glass fiber composites possess superior quality compared with most composites. Epoxy resin is primarily used as matrix in the processing of glass fiber composites due to their wetting capability and ability of cohesion to glass fiber for thermal properties and tensile strength [2].

Scientists generally focus on the enhancement of mechanical and thermal properties of composite material. The presence of nanomaterials like graphene has substantial effect on the properties of both thermoplastic and thermosetting matrices. Epoxy is usual matrix material for the polymer type composite structures in the manufacturing process. Epoxy is widely used in fiber reinforced polymers, and it improves certain properties

*corresponding author; e-mail: canyurt@gazi.edu.tr such as toughness, strength, cost, coefficient of friction, adhesion strength, and performance at elevated temperatures $[3,4]$. Epoxy becomes stronger in terms of mechanical properties by addition of nanoparticles. In the layered composite structures, the adhesive region forming the inter layers is a problematic region. Peeling and breakage between layers cause damage to the structure. It is possible to increase the mechanical properties in this region by adding nanoparticles into the adhesives. This prevents these regions from becoming a problematic region.

The benefit of using carbon based nano materials as additives in polymer composite structures has been extensively substantiated due to their elevated mechanical properties [5]. Especially graphene has been examined intensely in recent years due to exceptional mechanical properties since its discovery in 2004 [6]. The use of graphene in glass fiber composites played positive roles for various industrial applications [7-9].

In this study, an addition of graphene nanoparticles on the glass fiber composite structure was investigated experimentally. Two types of angle-oriented sandwich structures and different amount of nanoparticle addition by weight were examined.

\section{Materials and experimental procedure}

Glass-fiber composites and epoxy resin were used as materials. Epoxy was a standard diglycidyl ether of bisphenol A and araldite LY 1564 was supplied by Huntsman, Switzerland. E-glass fiber fabric was a unidirectional fabric $0^{\circ}$ pattern with an areal weight of $330 \mathrm{~g} / \mathrm{m}^{2}$ and 1200 TEX, obtained from Huntsman, Switzerland. The graphene nanoparticles that had an outer diameter and thickness of 10-20 nm were obtained from Ege Nanotek Chemical Industry Ltd., Izmir, Turkey. 


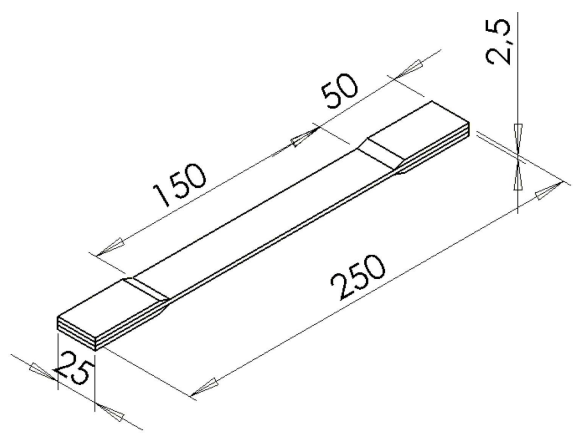

Fig. 1. Standard tensile test sample.

The matrix between the layers was formed by mixing the epoxy with hardener with the weight ratio of 100:80. Graphene nanoparticles was added into the matrix using $0.1 \%, 0.3 \%$, and $0.5 \%$ by weight configurations and mixtured by Hielscher UP400S ultrasonic mixed in order to have homogeneous mixture. Matrix mixture was applied between oriented fiber layers in order to construct 9 layers. The fiber orientation angles for glass fiber composite materials are extremely important. While $0^{\circ}$ angle withstands for unidirectional forces, $90^{\circ}$ angle withstands for lateral forces. Two types of angle-oriented sandwich structures were constructed, called type A that has three layers of $0^{\circ},\left(0^{\circ} /+45^{\circ} /-45^{\circ} / 90^{\circ} / 0^{\circ} / 90^{\circ} /-45^{\circ}\right.$ $/+45^{\circ} / 0^{\circ}$ angles $)$, and type $\mathrm{B}$ that has two layers of $0^{\circ}\left(90^{\circ} /+45^{\circ} /-45^{\circ} / 0^{\circ} / 90^{\circ} / 0^{\circ} /-45^{\circ} /+45^{\circ} /\right.$ $90^{\circ}$ angles). 9 layers of fiber layup and mixture of matrix were cured at $135^{\circ}$ under 6 bar hot mold press pressure for $2 \mathrm{~h}$. Nominal thickness of samples was measured as $2.5 \pm 0.2 \mathrm{~mm}$. The dimensions of the test specimens can be seen in Fig. 1.

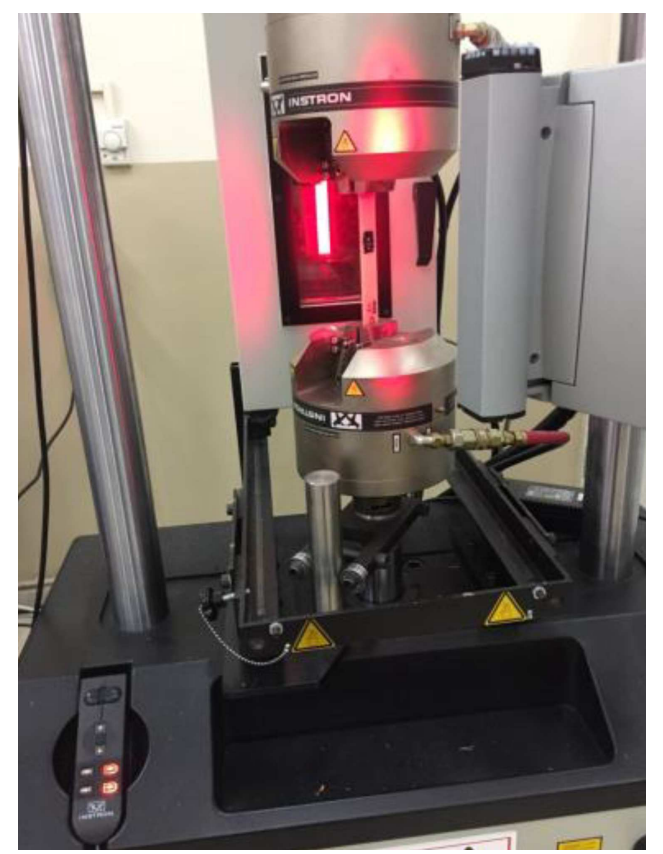

Fig. 2. INSTRON 8801 universal unidirectional test machine.
Uniaxial tests were performed according to ASTM D 3039 international standard [10], using the INSTRON testing machine 8801 series that have $50 \mathrm{kN}$ load capacity, shown in Fig. 2. Quasi-static loading was performed for all samples with speed of $0.5 \mathrm{~mm} / \mathrm{min}$.

\section{Results and discussion}

The mechanical strength of the E-glass/epoxy composite plates supported with nanoparticles, with particle weight fractions of $0,0.1,0.3$, and $0.5 \mathrm{wt} \%$, were determined for type A and type B structures, and then the critical tensile strength loads of the glass fiber composite sandwich structures were investigated experimentally. Mechanical characterizations of layered composite structures with nanoparticle additive were explored for different weight contents of graphene. Tensile stress-axial strain relations are displayed in Fig. 3. Graphene ratio of $0.1 \mathrm{wt} \%$ showed stiff behavior compared with other graphene ratios.
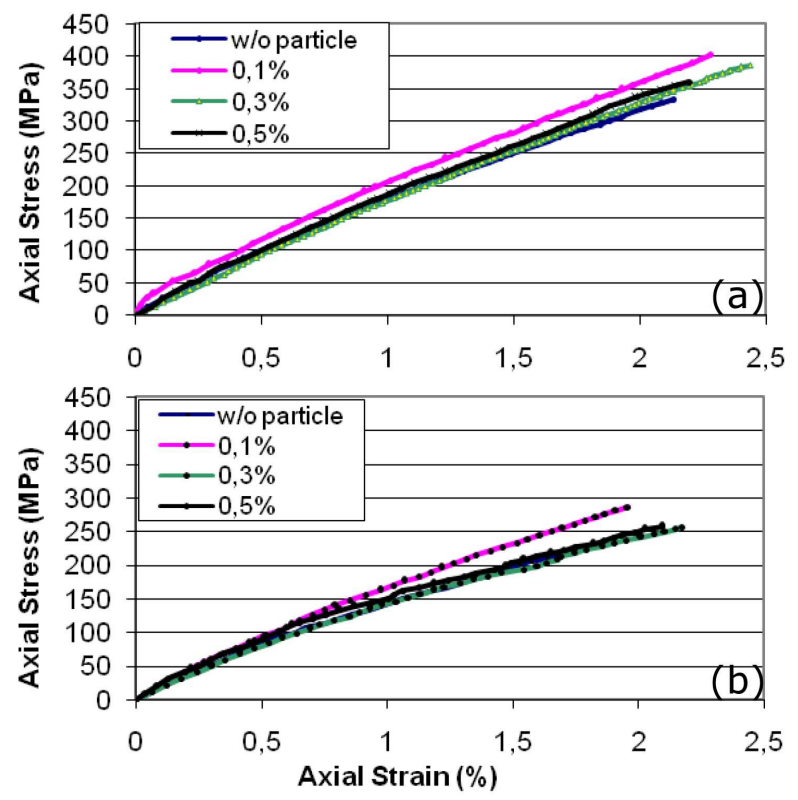

Fig. 3. Axial stress-axial strain curves of tests samples: (a) type $\mathrm{A} 0^{\circ} /+45^{\circ} /-45^{\circ} / 90^{\circ} / 0^{\circ} / 90^{\circ}$ $-45^{\circ} /+45^{\circ} / 0^{\circ}$, (b) type B $90^{\circ} /+45^{\circ} /-45^{\circ} / 0^{\circ}$ $/ 90^{\circ} / 0^{\circ} /-45^{\circ} /+45^{\circ} / 90^{\circ}$.

It can be noted here that all samples showed the brittle behavior along the tensile stress-axial strain curves and addition of graphene additive in the epoxy resin initiated to increase toughness of the samples. Both composite structures showed maximum strength at $0.1 \mathrm{wt} \%$ graphene addition, due to better surface interactions between epoxy resin and graphene nanoparticles. Graphene addition of $0.1 \mathrm{wt} \%$ led to increase of $20.6 \%$ and $21.8 \%$ in the strength of composite material for type A (Fig. 3a) and type B (Fig. 3b) structures, respectively. After increasing graphene ratio to $0.3 \mathrm{wt} \%$, the strength value started to decrease. This shows that an optimum point 
exists in terms of addition of nanoparticles. Type A sandwich structure that has one more $0^{\circ}$ fiber ply compared with type B showed stiffer and stronger behavior. As shown in Fig. 4, when the number of $0^{\circ}$ angle fiber increased, the strength of the polymer matrix composite materials increased by about $47 \%$.

The morphology was examined by scanning electron microscopy (SEM) that illustrate the failure of matrix and glass fibers in the fracture zone. Failure of fibers

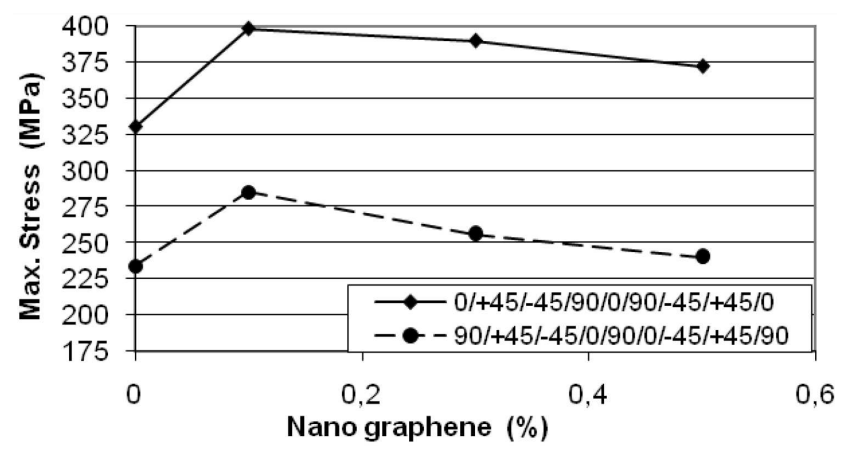

Fig. 4. Effect of graphene contribution by weight on the tensile strength.
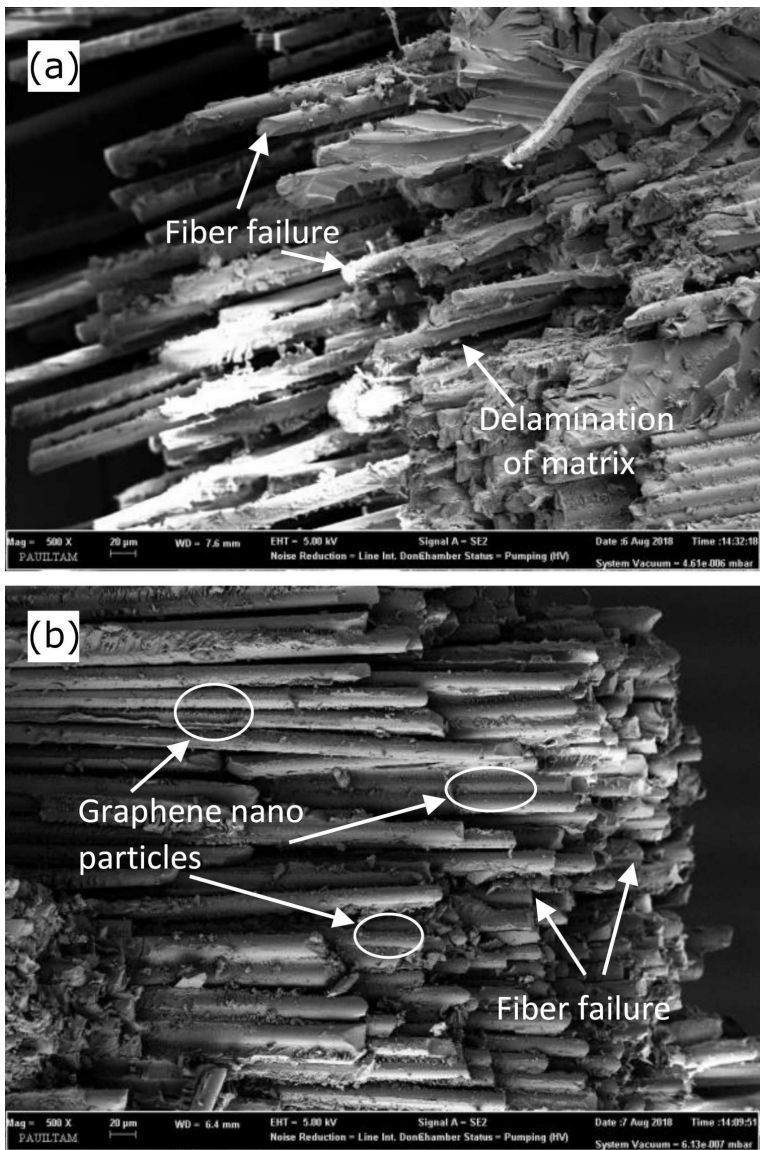

Fig. 5. SEM images of the fracture zone: (a) absence of nanoparticles, (b) presence of graphene nanoparticle additive. and delamination of matrix in absence of nanoparticles and the addition of graphene nanoparticles are presented in Fig. 5a and b, respectively. The fracture micro mechanism in glass fibre/epoxy resin was mainly due to fiber failure and interfacial debonding. A considerable plastic deformation and an amount of resin adhering to the glass fiber surface were seen on the fracture zone. The fibers completely detach from matrix due to weak adhesion. Polymer matrix materials and subsequent formation of particle through the graphene nanoparticle addition can significantly affect the overall strength and properties of a given composite without materially affecting the chemistry. The development of the microstructure should be related to the interaction between the nanographene and epoxy resin. Although it was ensured that the matrix was better adhered to the fiber with the addition of the sufficient nanoparticle, the addition of excess additive caused a decrease in the strength of layered composite structures such as notching or hole effect in the matrix.

\section{Conclusion}

The morphology obtained by SEM that illustrate the fracture micromechanism in glass fibre/epoxy resin was mainly due to fiber failure and interfacial debonding. The addition of graphene nanoparticles affected the strength of the layered composite materials. The proper amount of graphene particles addition increased the strength of composites. Using optimum amount of graphene nanoparticles showed better adhesion properties by adhering with epoxy resin. The amount of $0.1 \%$ and $0.3 \%$ graphene additive led to $20 \%$, and $18 \%$ increase in the composite strength for type A and $22 \%$ and $9 \%$ increase for type B angle oriented composite sandwich structure. An optimum graphene amount exists in the materials and excess amount of graphene nanoparticles additive caused a decrease in the strength of layered composite structures. Optimum amount of graphene was found to be $0.1 \mathrm{wt} \%$. It was concluded that load carrying capability of composites was significantly influenced by graphene nanoparticles.

\section{Acknowledgments}

This study was supported by the Unit of Scientific Research Projects (USRP) of Pamukkale University. Project number is 2017FEBE065. The authors express their thanks to Pamukkale University for their kind supports.

\section{References}

[1] P.C.L. Baron, Z. Wang, T.J. Pinnavaia, Appl. Clay Sci. 15, 11 (1999).

[2] P.K. Mallick, Fibre Reinforced Composites: Materials, Manufacturing and Design, 2nd ed., Marcel Dekker, New York 1993, p. 74.

[3] E. Roussi, A. Tsetsekou, D. Tsiourvas, A. Karantonis, Surf. Coat. Technol. 205, 3235 (2011). 
[4] P. Samyn, P.D. Baets, W.V. Paepegem, J. Degrieck, L.V. Schepdael, A. Gerber, J.S. Leendertz, Lubricat. Sci. 12, 119 (2006).

[5] X. Sun, H. Sun, H. Li, H. Peng, Adv. Mater. 25, $5153(2013)$

[6] A.C. Ferrari, F. Bonaccorso, V. Fal'ko, K.S. Novoselov, S. Roche, P. Boggild, Nanoscale 7, 4598 (2015).

[7] T. Kuilla, S. Bhadra, D. Yao, N.H. Kim, S. Bose, J.H. Lee, Progr. Polym. Sci. 35, 1350 (2010).
[8] M. Bulut, Composites B 122, 71 (2017).

[9] H. Mahmood, L. Vanzetti, M. Bersoni, Composites A Appl. Sci. Manufact. 107, 112 (2018).

[10] ASTM D3039, Standard test method for tensile properties of polymer matrix composite materials, American Society for Testing and Materials, 2014. 